Indian J Anim Health (2022), 61(1): 172- 174

DOI: https://doi.org/10.36062/ijah.2022.11221

\title{
Successful management of concurrent hypokalemia and polioencephalomalacia in a heifer
}

\author{
K. Sasikala ${ }^{1}$, S. Sivaraman ${ }^{2 *}$, E. Venkatesakumar ${ }^{1}$, R. Ravi ${ }^{1}$ and P. K. Ramkumar ${ }^{1}$ \\ ${ }^{1}$ Department of Veterinary Clinical Medicine, Veterinary College and Research Institute, Namakkal \\ - 637 002, Tamil Nadu, India; ${ }^{2}$ Veterinary Clinical Complex, Veterinary College and Research Institute, \\ Namakkal - 637 002, Tamil Nadu, India
}

\begin{abstract}
A one year old Jersey crossbred heifer was presented to Veterinary Clinical Complex, Veterinary College and Research Institute, Namakkal, with a history of the distended abdomen, lateral recumbency and accidental ingestion of rice three days back. Clinical examination revealed dullness, sunken eyeballs and fluid splashing sounds of rumen. Milky grey rumen liquor with reduced $\mathrm{pH}$ and absence of protozoa were observed on rumen fluid examination. The animal was administered with sodium bicarbonate in normal saline. The animal was weak, unable to lift its head and in sternal recumbency after therapy. Serum biochemistry revealed hypokalemia, and the heifer was administered with potassium chloride syrup. The animal showed nystagmus with normal vital signs after therapy. Haemato-biochemical parameters were within the normal range. The heifer was diagnosed for polioencephalomalacia as sequelae of ruminal lactacidosis, and thiamine was administered intravenously. The animal was an uneventful recovery after proper treatment.
\end{abstract}

Key words: Acidosis, Heifer, Hypokalemia, Polioencephalomalacia, Thiamine

\section{Highlights}

- Ingestion of rice in the heifer resulted in acute ruminal lactacidosis and was treated with sodium bicarbonate.

- Adminstration of sodium bicarbonate enhanced urinary excretion of potassium and resulted in hypokalemia.

- Persistent recumbency after sodium bicarbonate therapy should always consider hypokalemia.

- Hypokalemia could be safely and successfully treated with oral potassium supplements.

- Nervous signs with normal vital parameters after carbohydrate engorgement should always consider polioencephalomalacia and early treatment with thiamine increased the recovery.

Polioencephalomalacia, also known as cerebrocortical necrosis, was a most common and important non-infectious neurological disorder of ruminants that occurred in the grey matter of the brain. Polioencephalomalacia was more common in young feedlot cattle that were fed with high concentrate rations (Constable et al., 2017). Several etiological factors were associated with the diseases that include acute lead poisoning (Lemos et al., 2004), analogues such as amprolium (Santana et al., 2009a), thiamine deficiency, ingestion of plants rich in thiaminase (Santana et al., 2009b), sulfur intoxication (Amat et al., 2013), water deprivation sodium ion toxicosis (Duarte et al., 2014) and ruminal lactic acidosis from high carbohydrate diets (Sivaraman et al., 2016). Acidosis promotes the proliferation of thiaminase II producing bacteria and destroys thiamine which causes cerebrocortical necrosis (Rachid et al., 2011). The present article described successful management of concurrent hypokalemia and polioencephalomalacia in a Jersey crossbred heifer.

A one year old Jersey crossbred heifer was presented to Veterinary Clinical Complex,

Corresponding Author, E Mail: smavanthi@gmail.com 
Table 1. Haemato-biochemistry before and after therapy

\begin{tabular}{lllccc}
\hline $\begin{array}{l}\text { Sl. } \\
\text { No. }\end{array}$ & Parameters & Normal & $\begin{array}{c}\text { Day 1 of } \\
\text { presentation }\end{array}$ & $\begin{array}{c}\text { After } \\
\text { NaHCO3 } \\
\text { therapy }\end{array}$ & $\begin{array}{c}\text { After } \\
\text { KCl } \\
\text { therapy }\end{array}$ \\
\hline 1. & Haemoglobin (g/dL) & $8.0-15$ & 15.92 & 11.20 & 10.10 \\
2. & PCV (\%) & $24-46$ & 47.62 & 39.87 & 35.26 \\
3. & RBC (x 10 /cumm) & $5.0-10$ & 10.69 & 10.01 & 8.67 \\
4. & WBC (x 10 $\left.10^{3} / \mathrm{cumm}\right)$ & $4.0-12$ & 8.83 & 8.12 & 8.12 \\
5. & Neutrophils (x 103/cumm) & $0.6-4.0$ & 3.12 & 1.64 & 1.64 \\
6. & Lymphocytes (x 103/cumm) & $2.0-7.5$ & 5.24 & 5.12 & 5.12 \\
7. & Monocytes (x 103/cumm) & $0-0.8$ & 0.47 & 0.40 & 0.40 \\
8. & Calcium (mg/dL) & $9.7-12.4$ & 11.30 & 10.70 & 10.60 \\
9. & Phosphorus (mg/dL) & $5.6-6.5$ & 6.10 & 5.80 & 5.90 \\
10. & Magnesium (mg/dL) & $1.8-2.3$ & 2.20 & 2.20 & 2.10 \\
11. & Glucose (mg/dL) & $45-75$ & 62 & 69 & 118 \\
12. & Potassium (mEq/L) & $3.9-5.8$ & 4.10 & 2.70 & 3.90 \\
\hline
\end{tabular}

Veterinary College and Research Institute, Namakkal, with a history of the distended abdomen, lateral recumbency and accidental ingestion of rice three days back. Clinical examination revealed dullness, sunken eyeballs, tachycardia, tachypnoea, lateral recumbency and fluid splashing sounds on succussion of the left paralumbar fossa. Haemato-biochemical analysis revealed elevated PCV with normal serum levels (Table 1). Milky grey, watery, sour odour rumen liquor with reduced $\mathrm{pH}$ (5) and absence of protozoa were observed on rumen fluid examination. Rumen was lavaged with a rumen fluid extraction pump, and the heifer was administered with sodium bicarbonate (7.5\%) diluted in normal saline (@ $10 \mathrm{~mL} / \mathrm{kg} \mathrm{IV}$ ).

The animal showed transient improvement following therapy but exhibited generalized muscle weakness, could not lift its head and was in sternal recumbency. Serum biochemistry revealed hypokalemia, and the heifer was administered with potassium chloride syrup (Potklor@ $0.2 \mathrm{~g} / \mathrm{kg}$ BID PO) for two days. Animal exhibited sternal recumbency, torticollis (Fig. 1), nystagmus, bruxism, tachycardia, absence of menace reflex with normal pupillary light reflex and palpebral reflexes. Urinalysis was negative for ketone bodies, and peripheral blood smear examination was negative for blood protozoan diseases. Improvement in feeding habits with normal vital signs and haemato-biochemical parameters were observed. Based on the history of carbohydrate feeding, clinical signs and normal laboratory findings, the diagnosis of polioencephalomalacia as sequelae of ruminal lactacidosis was made.

The heifer was symptomatically treated with thiamine (@20 mg/kg BID IV) in normal saline, mannitol (@1g/kg IV) and dexamethasone (@ $0.5 \mathrm{mg} / \mathrm{kg} \mathrm{IM}$ ) for two days. Heifer showed marked clinical improvement with normal eye reflexes after 12 hours of therapy. The animal was lifted using a whole-body sling, and all the limbs were massaged. The animal made an uneventful recovery with a normal gait after 2 days of treatment (Fig. 2).

Polioencephalomalacia is characterized pathologically by cerebral oedema, laminar necrosis of the cerebral cortex and foci of necrosis throughout the brain (Holt, 1988).

Large doses of sodium bicarbonate therapy for acute ruminal lactacidosis increased delivery of $\mathrm{Na}^{+}$and $\mathrm{HCO}_{3}^{-}$ions to the distal nephron. These enhanced urinary potassium excretion 
by increasing distal tubular flow caused hypokalemia (DiBartola, 2006). Hypokalemia due to sodium bicarbonate therapy for ruminal lactacidosis in the present study was supported by Sasikala and Vijayakumar (2018). Clinical signs of muscle weakness caused by lowered resting membrane potential resulted in decreased excitability of neuromuscular tissue in hypokalemia and torticollis, nystagmus and absence of menace reflex in polioencephalomalacia in the present case were in concurrence with Constable et al. (2017). Immediate response to thiamine therapy was diagnostic at field level to differentiate it from other neurological conditions (Mahajan et al., 2011). A higher dose of thiamine (10-20 mg/ $\mathrm{kg}$ IV) is necessary for treating PEM due to its water solubility and urinary excretion (Cebra and Cebra, 2004; Constable et al., 2017).

It was concluded that differential diagnosis of persistent recumbency after sodium bicarbonate

\section{REFERENCES}

Amat S, Olkowski AA, Atila M and O'Neill TJ, 2013. A review of poliencephalomalacia in ruminants: is the development of malacic lesions associated with excess sulfur intake independent of thiamine deficiency? Vet Med Anim Sci, 1: 1-10, doi: 10.7243/2054-3425-1-1

Cebra CK and Cebra ML, 2004. Altered mentation caused by polioencephalomalacia, hypernatremia, and lead poisoning. Vet Clin North Am Food Anim Pract, 20(2): 287-302, doi: 10.1016/ j.cvfa.2004.02.003

Constable PD, Hinchcliff KW, Done AH and Grunberg W, 2017. Veterinary Medicine. A Textbook of the Diseases of Cattle, Horses, Sheep, Pigs and Goats. $11^{\text {th }}$ edn., W.B. Saunders Elsevier, Philadelphia, pp 1690-1693

DiBartola SP, 2006. Fluid, Electrolyte and Acid Base Disorders in Small Animal Practice. $3^{\text {rd }}$ edn., St. Louis, Missouri, Elsevier, Philadelphia, pp 101-107

Duarte MD, Bezerra J, Lima DHS, Bomjardim HA, Oliveira CMC et al., 2014. Salt poisoning outbreak in sheep in the state of Para. Pesq Vet Bras, 34: 1061-1068

Holt E, 1988. Polioencephalomalacia: case report and review. Bovine Pract, 23: 176-178 therapy should always include hypokalemia. Oral administration of potassium chloride was found to be effective and safe in treating hypokalemia. Polioencephalomalacia could be diagnosed based on the clinical signs as elaborative laboratory tests were not possible under field conditions. Early treatment with thiamine increases the recovery in ruminants with PEM.

Conflict of interest: Authors have no conflict of interest in this study.

Author's contribution: KS \& SS: Attended and treated the case; EV, RR \& PKR: Gave suggestions in diagnosis and treatment.

\section{ACKNOWLEDGEMENT}

The authors are very thankful to the Dean, Veterinary College and Research Institute, Namakkal, for the facilities provided during the study.

Lemos RAA, Driemeier D, Guimaraes EB, Dutra IS, Mori AE et al., 2004. Lead poisoning in cattle grazing pasture contaminated by industrial waste. Vet Hum Toxicol, 46(6): 326-328

Mahajan S, Agarwal R and Rashid SM, 2011. Diagnosis and management of polioencephalomalacia in Indian buffaloes under farm conditions. Buffalo Bull, 30(1): 6-9

Rachid MA, Filho EF, Carvalho AU, Vasconcelos AC and Ferreira PM, 2011. Polioencephalomalacia in cattle. Asian J Anim Vet Adv, 6(2): 126-131, doi: 10.3923/ajava.2011.126.131

Santana FJF, Lemos RAA, Nogueira APA, Togni M, Tessele B et al., 2009b. Polioencephalomalacia in ruminants. Pesq Vet Bras, 29: 681- 694

Santana FJF, Nogueira APA, Souza RIC, Cardinal SG, Lemos RAA et al., 2009a. Experimentally amprolium induced polioencephalomalacia in sheep. Pesq Vet Bras, 29: 747-752

Sasikala K and Vijayakumar G, 2018. Successful management of hypokalemia in a Holstein Friesian crossbred cow. Indian Vet J, 95(12): 54- 56

Sivaraman S, Vijayakumar G, Venkatesakumar E and Ponnusamy KK, 2016. Clinical management of polioencephalomalacia in goats - A retrospective study of 18 cases. Indian Vet J, 93(5): 70-72

Received - 12.10.2021, Accepted - 26.01.2022, Published - 17.02.2022 (Online), 01.06.2022 (Print)

Section Editor: Dr. A. K. Patra, Associate Editor 